\title{
A linguística saussuriana e a multiplicidade das línguas
}

\author{
Fernando Silva e Silva ${ }^{1}$
}

\section{Resumo}

Este trabalho aborda a ciência saussuriana de maneira bistórica e filosófica, de modo a oferecer uma leitura da obra de Ferdinand de Saussure que destaca a concep̧cão que o autor possuía da lingua e da linguagem, atravessada por conceitos não tão comumente enfatizados nos estudos saussurianos, em especial a analogia e o virtual. Através desses conceitos, o fenômeno linguístico apresenta-se de forma muito peculiar na obra do linguista, pois trata-se de um fenômeno extremamente fluido e mutável no espaço, no tempo e nas comunidades falantes. Finalmente, mostro como boa parte do interesse de Saussure, e do desafio da atividade do linguista para ele, está em desenvolver um instrumental conceitual - e um entendimento filosófico - que o babilite a momentaneamente capturar os fluxos da lingua fugidia e múltipla para descrevê-la a partir de suas características imanentes.

Palavras-chave: Ferdinand de Saussure. Teoria linguística. Analogia. Virtual. Multiplicidade

\footnotetext{
${ }^{1}$ Doutorando em filosofia do PPGFIL/PUC-RS. Mestre em Estudos da Linguagem pelo PPGLET/UFRGS.
} Graduado em Licenciatura em Francês na UFRGS. 


\section{Introdução}

O centro da ciência saussuriana da linguagem é o falante. Já é, penso, passada a hora de isso se tornar um lugar comum, um aposto trivial que acompanha as menções a Saussure em manuais e textos científicos diversos, e não uma espécie de desafio à tradição, o qual precisa ser seguido por uma série de referências aos mais diferentes autores na esperança de sustentálo - em suma, uma caixa preta ${ }^{2}$. Poderíamos invocar aqui décadas de trabalhos de pesquisadores como Claudine Normand, Christian Puech ou Henri Meschonnic, mas basta relermos o Curso de linguística geral para atestarmos isso.

Ao tratar das distintas capacidades de análise linguística do linguista e do falante, Saussure sentencia que "em última instância [...], a [análise] dos falantes é a única que importa, pois está fundada diretamente nos fatos de língua” (SAUSSURE, 2006, p. 213). Isso não significa, é evidente, uma superioridade de conhecimentos científicos da parte dos falantes sobre os linguistas. O que está em jogo para Saussure é o fato de que o linguista, analisando uma língua estrangeira, sua contemporânea ou não, jamais possui o mesmo discernimento do falante (como sua rápida pesquisa de campo na Lituânia o ensinou). "Sem dúvida, os falantes não conhecem essas dificuldades; tudo o que for significativo num grau qualquer aparece-lhes como um elemento concreto, e eles o distinguem infalivelmente no discurso" (SAUSSURE, 2006, p. 123). Decorre dessa precedência da experiência do falante que "a Linguística sincrônica só admite uma única perspectiva, a dos falantes” (SAUSSURE, 2006, p. 247).

Não seria tarefa impossível, mesmo dessas poucas passagens, extrapolar uma conceituação saussuriana do sujeito e de seu lugar na linguagem, dada a ênfase conferida ao aqui e agora do falante como critério de discernimento de "tudo o que for significativo". No entanto, esse não é o foco deste trabalho. Para os efeitos deste texto, basta reconhecer a presença e a importância conferida na teoria saussuriana ao falante. Se é um uso proveitoso ou não para estudos discursivos, pragmáticos, da conversação e outros que privilegiem o falante, essa é uma questão no momento secundária. O fato do conceito de falante e seus conexos terem sido historicamente deixados de lado diz respeito a um gesto interpretativo do

\footnotetext{
${ }^{2} \mathrm{Na}$ filosofia da ciência de Bruno Latour (2011), uma caixa preta é todo conceito, instrumento, entidade, artefato etc. cuja existência não está aberta para questionamentos. Essas certezas fundamentam nossa interpretação do cotidiano e no caso específico do fazer científico, servem para que cada empreitada não tenha sempre que começar ab ovo, seja na forma de instrumentação material ou conceitual.
} 
estruturalismo e não a algo essencial do pensamento do genebrino. Como diz Christian Puech: “Uma vez admitido que a ideia de um 'Saussure fundador do estruturalismo’ não é mais do que um atalho cômodo, acreditamos que o destino do saussurismo não estará encerrado de uma vez por todas" (2005, p. 110, tradução minha). Sendo assim, o objetivo deste artigo é dar destaque a algumas noções saussurianas - já presentes no Curso de Linguística Geral, mas cujo potencial radical tornou-se mais claro a partir da publicação dos Escritos de linguística geral - que tendem a ser deixadas em segundo plano, a saber, as de analogia e virtualidade. Situo também a relação dessas noções com outras mais conhecidas como os eixos sintagmático e associativo, os recortes sincrônico e diacrônico, etc., além de propor enquadrar essas noções em um problema mais geral da temporalidade da linguagem e, por conseguinte, da ciência linguística. O objetivo é subsidiar a compreensão da linguística saussuriana como uma ciência que busca dar conta do fenômeno linguístico em sua multiplicidade constitutiva - algo, ao menos para Saussure, evidente e constatado empiricamente na experiência do(s) falante(s) o tempo todo e demonstrar que isso exige não apenas um rearranjo epistemológico da parte do genebrino, mas também uma inovação ontológica.

O lugar do falante no pensamento de Saussure suscita dois tipos de reflexão estreitamente relacionadas. Primeiramente, reflexões acerca dos processos psicológicos engendrados pela faculdade da linguagem, o que nos traz conceitos como sintagmático, associativo, analogia e valor. Em segundo lugar, há uma reflexão sobre o todo da atividade linguística, centrado na ideia de sistema relacional, signo/unidade, na relação entre virtual e atual e nos recortes temporais da sincronia e da diacronia. O primeiro grupo de conceitos, podemos considerá-lo apropriado para iniciar a abordagem de textos particulares e ao segundo cabe descrever o quadro em que os textos particulares se inscrevem. Não sugiro, porém, interpretar o recorte proposto relacionando-o aos conceitos de língua e fala, pois, penso que a problematização a seguir, finalmente, ultrapassa essa distinção.

\section{Fazer do eu-aqui-agora da língua um objeto de ciência}

O segundo grupo de conceitos que delimitei - a saber, sistema, signo, virtual e atual, sincronia e diacronia - contém uma das principais particularidades da revolução saussuriana, a 
saber, sua maneira de tratar a temporalidade na ciência linguística. Expressa de forma condensada no arbitrário linguístico, a noção de tempo em Saussure foi historicamente por vezes um problema silencioso, noutras vezes gritante, às vezes ambos ao mesmo tempo. Como se sabe, Émile Benveniste lê a noção equiparando arbitrário a contingente e opondo-o a necessário em seu célebre artigo de 1939. Para Claudine Normand, em um artigo dedicado à noção de arbitrariedade, se trata de um “"acerto de contas' com a antiga filosofia da origem (ainda em funcionamento de maneira mais ou menos explícita na linguística histórica)" (1973, p. 123, tradução minha). Segundo a autora, havia na época uma ênfase excessiva sobre o arbitrário que, com efeito, não apresentaria grande novidade, sendo apenas uma retomada do velho debate entre convenção e natureza, enquanto se deixava de lado o conceito verdadeiramente inovador, o de valor. É Henri Meschonnic quem alia o arbitrário linguístico (não apenas do signo, mas da linguagem inteira) ao problema da temporalidade de maneira decisiva. Para o autor, é apenas a partir do arbitrário que se torna possível para a linguística pensar a historicidade radical da linguagem, a inscrição de todo ato de linguagem em um euaqui-agora. Na interpretação de Meschonnic, o arbitrário é a solução que Saussure encontra para imaginar um sistema linguístico nem contingente e nem necessário, nem convencional e nem natural, mas sim histórico, social e subjetivo (MESCHONNIC, 1982, p. 29)33. Para compreender sua posição, é necessário entender que "o caráter radicalmente arbritário do signo (que não é a 'imotivação') implica a relação sistema/valor” (CHISS, 1978, p. 101, tradução minha), ou seja, o arbitrário é mais do que mera propriedade intrínseca do signo linguístico, o laço imotivado de suas partes. Christian Puech faz uma associação similar entre sistema linguístico, subjetividade e história, ao lembrar que desde as primeiras recepções da obra do genebrino, e com o Curso de Linguística Geral especialmente, "a afirmação saussuriana do 'caráter social dos fatos linguísticos' constituiu menos um programa do que um desafio: pensar ao mesmo tempo a sistematicidade da língua, o estatuto do sujeito e a variabilidade da história” (2005, p. 110, tradução minha).

\footnotetext{
${ }^{3} \mathrm{O}$ que não quer dizer que os conceitos de contingência e necessidade estejam de todo ausentes da obra saussuriana, mas concordo com Meschonnic quando os afasta da interpretação do arbitrário. O contingente podemos encontrar, por exemplo, quando Saussure trata da mudança linguística, em especial a fonética. Para ele, não há qualquer tipo de causa explícita ou implícita para as transformações linguísticas (a analogia, igualmente, não é considerada uma causa). O necessário se vê, é evidente, nos conceitos fundamentais de sua teoria linguística. Todos os conceitos principais se engendram mutual e necessariamente.
} 
Essa historicidade radical é expressa de todo no conceito de sincronia. Como brinca Jean-Louis Chiss: "se puxamos o fio da sincronia, todo o tricô do CLG se desfaz" (1978, p. 92, tradução minha). Essa afirmação vai contra a convenção estruturalista (e de sua crítica) de uma primazia da sincronia sobre a diacronia que, por sua vez, implicaria uma primazia da descrição ahistórica da língua. A valorização da sincronia na epistemologia saussuriana tem uma pretensão realista, isto é, de dar conta de um fato observado; a língua e a história se desenrolam no tempo, é certo, mas elas, em um momento dado, único, acontecem (na forma de discurso e historicidade, conceitos pouco usados por Saussure, mas pertinentes para a compreensão da distinção em questão). Retornamos assim à centralidade do falante. É no e pelo falante que a língua, e por conseguinte a história, acontecem:

A sincronia conhece somente uma perspectiva, a das pessoas que falam, e todo o seu método consiste em recolher-lhes o testemunho; para saber em que medida uma coisa é uma realidade, será necessário e suficiente averiguar em que medida ela existe para a consciência de tais pessoas (SAUSSURE, 2006, p. 106).

Dessa maneira, “a sistematicidade não é, nem de longe, uma negação da 'História', mas apenas do evolucionismo" (CHISS, 1978, p. 99, tradução minha). Meschonnic faz uma afirmação similar, resgatando também a constituição disciplinar da linguística saussuriana e, a partir daí, propondo uma crítica do estruturalismo: "sistema, que é o termo de Saussure, é histórico, na medida em que não separa filologia e linguística [...]. Enquanto estrutura é ahistórico e só é capaz de deshistoricizar. Nesse aspecto, nada está mais oposto a Saussure do que sua posteridade estruturalista" (1982, p. 29, tradução minha).

Já se pensou que o sistema linguístico saussuriano comportasse, por definição, apenas leis, em sentido prescritivo. No entanto, nas claras palavras do próprio Saussure: "falar de lei lingüística em geral é querer abraçar um fantasma” (SAUSSURE, 2006, p. 107). No que diz respeito à sincronia, suas "leis" são apenas a distribuição dos usos em um dado recorte de tempo e espaço. Quanto ao léxico, se pensou tratar apenas de sentidos ditos próprios ou instituídos ou dicionarizados, devido a uma interpretação do signo como uma entidade pronta, no entanto, uma passagem de Sobre a essência dupla da linguagem nos confirma não ser o caso:

Mesmo que se trate de designações muito precisas como rei, bispo, mulher, cão, a noção completa envolvida na palavra resulta apenas da coexistência de outros termos; o rei não é mais a mesma coisa que o rei se existe um 
imperador, ou um papa, se existem repúblicas, se existem vassalos, duques, etc.; - o cão não é mais a mesma coisa que o cão quando é oposto a cavalo, representando, nesse caso, um animal impudente e ignóbil, como no tempo dos gregos, ou se é oposto sobretudo à fera selvagem que ele ataca, representando, neste caso, um modelo de intrepidez e fidelidade ao dever, como no tempo dos celtas (SAUSSURE, 2004, p. 73).

Como se nota, temos sentidos extremamente informados pela história e pela cultura. De que se ocupa então a diacronia? Tanto o CLG quanto os ELG hesitam nesse aspecto. Repetidamente, Saussure delimita objetos para a diacronia, mas o tempo todo relembra que a significação só ocorre, de fato, na sincronia, o que dissolve o objeto previamente estabelecido (CHISS, 1978, p. 104-106). É seguro afirmar, porém, que o recorte diacrônico serve para explicitar as mudanças de uma sincronia para outra. Diferente da sincronia, fundada no sistema como um todo, a diacronia se ocupa de unidades isoladas, mesmo que numerosas, e sua substituição de um sistema a outro. A "lei" diacrônica se atém a explicitar uma substituição como no exemplo: "[a]s sonoras aspiradas do indo-europeu se tornaram surdas aspiradas *dhumos > thumós" (SAUSSURE, 2006, p. 108) e sua aparência imperativa se deve ao fato de que é analisada do ponto de vista do fato consumado. Retomemos a passagem recém citada dos manuscritos saussurianos; "[o] rei não é mais a mesma coisa que o rei se existe um imperador". Se tratam aqui de três ordens de fatos: duas sincronias diferentes e uma constatação diacrônica. Há uma primeira sincronia em que "rei" possui um determinado valor, estabelecido em relação com tantos outros signos e há uma segunda sincronia em que "rei" tem um valor diferente, devido a uma reconfiguração das relações que definem o termo provocada pelo surgimento de "imperador". Dois fatos diacrônicos podem ser extraídos desse contraste de sincronias, o surgimento do novo termo "imperador" e a mudança do sentido de "rei". Dessa maneira, se compreende que a mudança é, em sua totalidade, uma preocupação da diacronia no que diz respeito à capacidade da ciência linguística em constatá-la. Sua origem, porém, Saussure o diz claramente, se dá no discurso: "[t]odas as modificações, sejam fonéticas, sejam gramaticais (analógicas), se fazem exclusivamente no discursivo. [...]. Toda inovação chega de improviso, ao falar, e penetra, daí, no tesouro íntimo do ouvinte ou no do orador [...]" (SAUSSURE, 2004, p. 87). No entanto, aí ela é ensaio, experimento e ainda que seja possível constatar concorrência na sincronia, não há substituição, pois, neste caso, se trataria de uma nova sincronia. 
A importância desse enquadramento temporal para a teoria saussuriana leva Jean-Louis Chiss a concluir até mesmo que "a distinção sincronia/diacronia aparece, mais do que a oposição língua/fala, como o passo fundador do projeto saussuriano” (1978, p. 101, tradução minha). Concordo com o autor na medida em que o estabelecimento de uma temporalidade própria é, sem dúvida, um dos principais passos para a construção de uma nova cientificidade para a linguística e o genebrino com certeza põe grande ênfase nesse aspecto de suas reflexões. Antes de fechar esse ponto, que se iniciou com o conceito de arbitrário radical, é importante destacar um outro aspecto do sistema linguístico de Saussure. Se já foi possível estabelecer a importância do tempo e entrever alguns aspectos do lugar do falante, ainda não dei atenção à espacialidade. Ainda que não pretenda analisar em detalhes esse aspecto, é impossível ignorar um ponto tão desenvolvido no CLG e nos diferentes materiais presentes nos ELG. O espaço tem para Saussure a mesma importância que o tempo no que diz respeito à diversidade das línguas. Com efeito, ele considera "a diversidade geográfica [...] a primeira comprovação feita em Linguística; ela determinou a forma inicial da pesquisa científica em matéria de língua, inclusive entre os gregos" (2006, p. 222). Essa afirmação não é trivial, pois dessa maneira o genebrino coloca a pesquisa dialetal acima das reflexões filosóficas gerais sobre a linguagem no que diz respeito à constituição da ciência linguística. Ainda enfatizando a diversidade, afirma: “[o] que primeiro surpreende no estudo das línguas é sua diversidade, as diferenças linguísticas que se apresentam quando se passa de um país a outro, ou mesmo de um distrito a outro" (2006, p. 221). Em uma de suas conferências proferidas em 1891, Saussure traz um exemplo bem prático de como diferentes sincronias distribuídas geograficamente realizam certos grupos sonoros em relação à sincronia latina:

[O] savoiano que parte na direção de Auvergne chega, ao fim de um certo tempo à fronteira de $\theta a$ para ca latino e encontrará, por exemplo, tsa, assim $t^{2} s^{2} a$, o que não o perturba muito e não o impede de compreender; algumas léguas depois, ele passa de uma outra fronteira, suponho, a de $p l$ que dá $p t$, isso também não o perturba; mas, na medida em que ele se afasta de sua aldeia natal, a soma das diferenças com relação ao seu dialeto se acumula e acaba por fazer com que ele não compreenda mais (SAUSSURE, 2004, p. 149).

Esse tipo de passagem, que encontramos também no Curso de Linguística Geral, ao ser reproduzida aqui, tem também o papel de relativizar a imagem estabelecida de Ferdinand de Saussure como um linguista de abstrações. Os conceitos que ele elaborou, como estou progressivamente apresentando ao longo deste artigo, são concebidos a partir da constatação 
das infinitas variações das línguas. Esse trecho traz ainda um outro ponto interessante, o problema da compreensibilidade interdialetal. Para o linguista: "[é] difícil dizer em que consiste a diferença entre uma língua e um dialeto" (2004, p. 235), o que o leva a concluir que "não existe, regularmente, fronteira entre o que se denomina duas línguas, por oposição a dois dialetos, quando essas línguas são da mesma origem e faladas por populações contíguas sedentárias. Por exemplo, não existe fronteira entre o italiano e o francês” (2004, p. 149), pois existe "entre os dialetos e as línguas uma diferença de quantidade, não de natureza" (2006, p. 223). A clara distinção entre dialetos, assim, é uma ilusão criada pelo pesquisador que se atém a apenas um ou outro aspecto de seu objeto de estudo. No Curso de linguística geral, ele afirma claramente:

Assim como não se poderia dizer onde termina o alto alemão e o platdeutsch, assim também é impossível traçar uma linha de demarcação entre o alemão e o holandês, entre o francês e o italiano. Existem pontos extremos nos quais se pode dizer, com segurança: 'Aqui impera o francês, aqui o italiano'; entretanto, quando entramos nas regiões intermediárias, vemos essa distinção se apagar (SAUSSURE, 2006, p. 236).

Dessa maneira, Saussure desafia a ontologia tradicional das línguas nacionais como modelos de expressão, imbuídas de um "gênio da língua" e imperando sobre os dialetos, vistos como degenerações repletas de corruptelas existentes no mesmo território. Aliás, não é apenas esse aspecto político que está presente em sua linguística geográfica. Saussure faz questão também de salientar a total independência entre língua e raça, isso em uma época em que tanto a linguística, quanto as outras ciências do homem, persistiam marcadas por concepções racistas.

Unindo então as dimensões analisadas, percebemos que, para Saussure, a língua não é apenas marcada por um eu-agora, mas também por um aqui. Assim, esse objeto possui uma dupla indefinição: “[A] língua que não é, como vimos, uma noção definida no tempo, não é, também, uma noção definida no [espaço]” (SAUSSURE, 2004, p. 149). Essa concepção se traduz em uma exigência metodológica: “[n]ão há outro meio de determinar o que queremos dizer, ao falar de tal ou tal língua específica, além de dizer a língua de Roma em tal ano; a língua de Annecy em tal ano. Ou seja, considerar uma única localidade pouco extensa em um único ponto no tempo" (SAUSSURE, 2004, p. 149). 
Até aqui me esforcei para respeitar a divisão de dois grupos de conceitos que fiz nos parágrafos iniciais, porém, para tratar do próximo tópico isso se torna impossível, pois a teorização sobre o virtual e o atual é justamente o ponto fulcral que liga o sistema sincrônico geral e a atividade individual do falante. Dessa maneira, tratando do último tópico desse grupo, já começo a tratar do primeiro tópico do primeiro grupo, o entrecruzamento das relações sintagmáticas e associativas.

\section{Dos eixos sintagmático e associativo à analogia e ao virtual}

Para Saussure, a mais importante ferramenta do linguista em sua atividade de pesquisa são as noções de sintagmático e associativo. Com efeito, para ele "[t]udo o que compõe um estado de língua pode ser reduzido a uma teoria dos sintagmas e a uma teoria das associações" (2006, p. 158). Essa hipótese jamais foi perseguida em sua radicalidade pelo estruturalismo ou outras correntes pós-saussurianas (ou até mesmo anti-saussurianas), pois ela coloca em questão os fundamentos milenares da gramática tradicional e propõe um grande desafio: o de redescobrir, língua a língua, as categorias essenciais da gramática, da sintaxe, da morfologia, enfim, de todo o sistema linguístico. Assim como "a distinção das palavras em substantivos, verbos, adjetivos etc., não é uma realidade linguística inegável” (2006, p. 127), também “[a] interprenetração da morfologia, da sintaxe e da lexicologia se explica pela natureza, no fundo idêntica, de todos os fatos de sincronia. Não pode haver entre eles nenhum limite traçado de antemão" (2006, p. 158).

Tendo a fala como base - novamente a centralidade do(s) falante(s) - é possível para o linguista, ao se utilizar das noções de sintagmático e associativo, reconstituir a língua de uma massa falante: "[p]ode-se dizer que a soma das classificações conscientes e metódicas feita pelo gramático que estuda um estado de língua sem fazer intervir a história deve coincidir com a soma das associações, conscientes ou não, postas em jogo na fala” (2006, p. 160). Nos aproximamos, assim, da relação entre atual e virtual. Aquilo que é posto em jogo na fala permite ao linguista entrever a soma de associações que compõe a língua. A clássica definição dos dois eixos permite que melhor compreendamos o papel das associações na constituição da fala: "[a] relação sintagmática existe in praesentia; repousa em dois ou mais termos igualmente 
presentes em uma série efetiva. Ao contrário, a relação associativa une termos in absentia numa série mnemônica virtual” (2006, p. 143). Como com o conceito de sincronia, a pretensão de Saussure com esses dois tipos de relação é possibilitar uma descrição realista da língua: “[s]omente a distinção [...] entre as relações sintagmáticas e as relações associativas sugere um modo de classificação que se impõe por si mesmo, o único que se pode pôr como base do sistema gramatical" (2006, p. 158). Para ele, esses instrumentos são equivalentes aos processos psicológicos do falante.

É fato conhecido que o estruturalismo fez do associativo o eixo paradigmático, um repositório de paradigmais flexionais, conjugacionais, etc. No entanto, o associativo saussuriano é uma virtualidade que engloba todas as possíveis associações que ocorrem na mente do falante no ato da produção de um sintagma. Nessa relação entre atual e virtual, se produzem os valores e, por conseguinte, os signos do sistema linguístico saussuriano. O conceito de virtualidade não é estabelecido na crítica saussuriana e isso não é de todo surpreendente, primeiramente por estar em contradição com a leitura estruturalista, em segundo lugar, porque ele aparece em múltiplas formas. Praesentia e absentia, como na citação acima, é uma das maneiras como essa distinção é expressa, assim como concreto e abstrato, positivo e negativo e efetivo e potencial. Uma dificuldade adicional é que esses conceitos, em especial os de concreto e abstrato e positivo e negativo, têm diversos usos com diferentes finalidades ao longo da obra saussuriana desde o Mémoire sur le système primitif des voyelles dans les langues indo-européennes. A teorização nos ELG na breve seção sobre a fala efetiva e a fala potencial revela, pela similaridade das definições, que os conceitos de sintagma e associativo foram forjados tendo em vista a atividade do falante:

Nós denominamos sintagma a fala efetiva,

- ou a combinação de elementos contidos numa seção da fala real, - ou o regime em que os elementos se encontram ligados entre si por sua sequência e precedência.

Por oposição à parallélie ou fala potencial, ou coletividade de elementos concebidos e associados pelo espírito, ou regime no qual um elemento leva uma existência em meio a outros elementos possíveis (SAUSSURE, 2004, p. 58 , grifos do autor).

A parallélie nessa passagem pode ser lida como sinônima de todas as relações associativas, mas a definição mais precisa apresentada na seção que lhe é dedicada exclusivamente, $\mathrm{n}^{\circ} 18$ nos ELG, indica que ela recobre apenas alguns dos tipos possíveis de 
associação. Como dito, esses dois tipos de relação produzem, a cada vez, todos os valores constitutivos do sistema linguístico:

A cada signo existente vem, então, SE INTEGRAR, se pós-elaborar, um valor determinado [ ], que só é determinado pelo conjunto de signos presentes ou ausentes no mesmo momento; e, como o número e o aspecto recíproco e relativo desses signos mudam a cada momento, de uma maneira infinita, o resultado dessa atividade, para cada signo, e para o conjunto, muda também a cada momento, numa medida não calculável (SAUSSURE, 2004, p. 80 , maiúsculas do autor).

É difícil ignorar a similaridade dessa passagem de Sobre a essência dupla da linguagem e a reflexão sobre as instâncias discursivas benvenistianas e a maneira como o sujeito coloca em movimento toda a linguagem em sua enunciação. Yong-Ho Choi (2002) faz uma interpretação similar e chama atenção para o uso do termo "determinado" na passagem acima, pois nota sua recorrência nos escritos saussurianos, destacando justamente a concepção de uma constante reelaboração de valores essencial ao funcionamento da língua/linguagem. É interessante também tomarmos as últimas palavras dessa passagem, "numa medida não calculável”, como mais do que uma força de expressão, mas sim uma atestação técnica. Isto é, uma atestação explícita de que o esforço de formalização da língua tem limites intrínsecos impostos pela própria natureza do funcionamento linguístico.

Destaco uma última passagem dos ELG sobre esse ponto, em que é possível ver a confluência de todos os pontos que apresentei até agora; retomando, a constituição dos valores através da evocação de associações que em seu total são negatividade, mas se manifestam de maneira positiva nos signos resultantes:

Os signos existentes evocam MECANICAMENTE, pelo simples fato de sua presença e do estado sempre acidental de suas DIFERENÇAS a cada momento da língua, um número igual não de conceitos, mas de valores opostos por nosso espirito (tanto gerais quanto particulares, uns chamados, por exemplo, de categorias gramaticais, outros tachados de fatos de sinonímia, etc.); essa oposição de valores, que é um fato PURAMENTE NEGATIVO, se transforma em fato positivo, porque cada signo, ao evocar uma antítese com o conjunto dos outros signos comparáveis em uma época qualquer, começando pelas categorias gerais e terminando pelas particulares, se vê delimitado, apesar de nós, em seu valor próprio (SAUSSURE, 2004, p. 80, grifos e maiúsculas do autor).

Leitura, Maceió, v. 1, no 62, jan./jun. 2019 - ISSN 2317-9945 
Como nos mostra a citação, os valores saussurianos são das mais variadas naturezas, posto que eles sustentem e são o produto das mais variadas combinações sintagmáticas e evocações associativas. Vemos que eles compreendem "categorias gramaticais" e "fatos de sinonímia”, mas estes são apenas alguns exemplos. Com efeito, passagens já citadas até aqui nos indicam isso, as relações que determinam esses valores constituem, em realidade, todos os valores do sistema linguístico.

O conceito de signo saussuriano parece ter sido concebido de início para dar conta dessa multiplicidade de valores em movimento. Todavia, no Curso de linguística geral, essa natureza movente do signo não se apresenta com clareza. Pode-se supor múltiplas razões para isso: a polissemia do termo "arbitrário" no texto, as representações visuais utilizadas para ilustrar o signo, os exemplos insuficientes e às vezes infelizes utilizados por Saussure, mas a principal razão, provavelmente, é a solidariedade que marca todos os conceitos desenvolvidos pelo mestre genebrino. Uma vez que um deles é aceito em sua radicalidade, os outros o acompanham. O modelo de signo que consta nos ELG, no entanto, representa melhor visualmente sua multiplicidade constitutiva que já era descrita no CLG. Saussure o chama de quatérnion final, devido à relação quádrupla que o define. Enquanto o signo usual é caracterizado pela união de um significante e um significado, o quatérnion tenta demonstrar o caráter sistêmico de todo signo, relacionando as partes do signo em questão com outros significantes e significados virtualmente presentes em sua composição. Visualmente, ao invés de $A / a$ - isto é, um significante que corresponde a seu significado - se trataria de uma relação entre $A / b c d$ e $X Y Z / a$ - um significante e um significado em uma relação cruzada, atravessada por outros significantes e significados (SAUSSURE, 2004, p. 39-40).

Chego então ao último conceito da teoria saussuriana de que tratarei neste artigo. No conceito de analogia convergem todos os outros que foram expostos até este momento, formando, acredito, a noção central que norteia a reflexão de Saussure sobre a atividade linguageira do falante. É preciso observar, no entanto, que é possível falar em pelo menos dois usos de analogia na obra saussuriana, próximos, mas com uma importante distinção. Por um lado, a analogia, ou "transformação inteligente" (SAUSSURE, 2004, p. 139), é o mecanismo através do qual o falante cria e recria continuamente a língua por meio da associação entre valores. Por outro lado, é um instrumento explicativo, conhecido na forma da quarta proporcional. Retornarei a essa diferença. 
Sobre o primeiro sentido, vale destacar uma passagem da Segunda conferência na Universidade de Genebra (novembro de 1891) em que é possível ver toda a importância que Saussure confere ao fenômeno da analogia:

eu digo logo de início, para que não haja nenhum mal-entendido sobre o valor que atribuímos a esses fatos: não são fatos excepcionais e anedócticos, não são curiosidades ou anomalias, mas a substância mais clara da linguagem, em qualquer parte e em qualquer época, a sua história de todos os dias e de todos os tempos (SAUSSURE, 2004, p. 140-141, grifo do autor).

Não seria possível afirmar de maneira mais enfática a importância da analogia. O aspecto mais interessante dessa definição é a compreensão dos fatos analógicos como "a substância mais clara da linguagem", pois reforça o que mostrei ao longo deste artigo que, na visão saussuriana, a matéria da língua ou da linguagem não são signos prontos, mas valores em criação. A positividade da linguagem são suas relações negativas, de diferença. Para Saussure, se trata mesmo do mecanismo pelo qual a criança, em seus anos formativos, se apropria da língua, como vemos no seguinte trecho: “[n]ão há melhor maneira de perceber o que é isso [a analogia] do que escutar falar, por alguns minutos, uma criança de três ou quatro anos. Sua linguagem é um verdadeiro tecido de formações analógicas” (2004, p. 139-140). Ainda mais, a analogia é também aquilo que faz com que a língua se transforme, ela é o próprio "princípio que não cessa de agir na história das línguas" (SAUSSURE, 2004, p. 140). Afora algumas transformações fonéticas, consideradas de todo contingentes por Saussure, as mudanças na língua se realizam todas através da "associação de formas no espírito, ditada pela associação das idéias representadas" (SAUSSURE, 2004, p. 140, grifos do autor) que é a analogia. Isso não quer dizer que haja teleologia nas transformações analógicas; pelo contrário, a principal divergência do estruturalismo de Praga com a diacronia saussuriana é a ausência de finalidade. Com efeito, qualquer tipo de teleologia seria totalmente contraditório com o que vimos até aqui sobre o pensamento de Saussure.

A definição da atividade do falante como criação serve também para afastar da linguística o fantasma da normatividade das gramáticas tradicionais. Para o mestre genebrino, a analogia nos mostra que "não se deve dizer nada; tudo o que se diz tem sua razão de ser" (2004, p. 141, grifo do autor), pois “[n]ão h[á] jamais criação ex nibilo, mas cada inovação [é] uma nova aplicação de elementos fornecidos pelo estado anterior da linguagem” (2004, p. 140). 
Com isso, retornamos ao instrumento da quarta proporcional. Ilustrado reconhecidamente com o exemplo da criação do vocábulo honor em latim no CLG, essa ferramenta serve para simular esse processo mental ao qual Saussure concede tanta importância, selecionando associações possíveis para ilustrar o raciocínio criativo. Assim, tratando da fala da criança, apresenta a simples equação "punir:punirai = venir:venirai", sendo venirai o elemento deduzido da relação anterior. Jamais se deve tomar esse dado, fora talvez no estudo de uma análise metalinguística do próprio falante, como o raciocínio de facto. Pois não se trata apenas da similaridade fônica e morfológica entre punir/venir que está envolvida na relação punirai/venirai, mas todos os outros verbos com conjugações semelhantes, todos os outros verbos com conjugações diferentes, as flexões dessas formas em outros tempos e modos, os empregos potenciais desses signos em sintagmas, etc., enfim, um misto de associações conscientes e inconscientes, in praesentia e in absentia, do qual nenhuma representação pode chegar nem perto, além dessa absoluta redução didática.

A analogia, então, completa o breve quadro da teoria saussuriana que quis construir neste artigo. Com seu auxílio, é possível ter uma compreensão ainda melhor da natureza da língua em Saussure. A realidade de uma língua é composta igualmente de sua atualidade e de sua virtualidade. Como vimos acima, o que Saussure chama de negatividade - mas que poderíamos entender ao invés como uma diferencialidade - sustenta a positividade da língua, pois "uma língua qualquer num momento qualquer nada mais é do que um vasto enredamento de formações analógicas" (2004, p. 140). Isto é, uma série de signos podem jamais ocorrer e mesmo assim ela constitui a realidade da língua, em sua virtualidade.

\section{A ciência saussuriana}

A ciência da linguagem saussuriana se propõe, finalmente, a oferecer um instrumental capaz de descrever qualquer língua/dialeto a que se tenha acesso, seja por material escrito ou oral. Há homologia quase que integral entre a metafísica da linguagem proposta por Saussure e a metodologia e os instrumentos de análise; isto é, como vimos no caso da analogia, os processos psicológicos do falante se confundem com os procedimentos de descrição. O 
mesmo pode ser dito do recorte temporal do arbitrário linguístico ou a constituição diferencial do sistema da língua.

A natureza da universalidade de sua teoria, como a configuro aqui ao menos, se diferencia de outras reflexões sobre a linguagem em vários pontos importantes. Primeiramente, pensemos em teorias que universalizam, transcendentalizando, teorias gramaticais. Podemos pensar nos gramáticos latinos e como eles importaram e traduziram categorias elaboradas para dar conta do grego ático. A proximidade gramatical das línguas e as adaptações realizadas pelos escritores das gramáticas possibilitou desenvolver o potencial epistemológico dessa relação entre as línguas. No entanto, a constituição da gramática clássica fez história e suas categorias foram tomadas pela própria metafísica da linguagem. Podemos ver isso desde a gramática de Port-Royal, na maneira com que a língua francesa é descrita, até os trabalhos dos missionários nas colônias europeias, com a imposição acrítica de categorias indo-europeias a línguas alheias nas gramáticas ad hoc que esses missionários elaboravam. Em uma versão mais contemporânea dessa forma de encarar a gramática, a linguística gerativa de Noam Chomsky faz um movimento similar, ao situar certos tipos de sintagma, verbais, nominais, na mente do falante. Outra forma de universalidade, bem representada entre as teorias da linguagem, é aquela que generaliza categorias lógico-argumentativas. Podemos encontrar essa atitude desde os filósofos gregos, passando novamente por Port-Royal, aos autores da semântica, da pragmática e da filosofia da linguagem em geral. As múltiplas perspectivas aqui apresentadas não permitem delimitar da mesma maneira uma diferença definitiva dessas abordagens com a teoria saussuriana, mas vale ressaltar a ausência da afirmação de quaisquer conteúdos determinados por parte do genebrino. Isto é, uma teoria saussuriana do sentido, da sociabilidade, não permitiria estabelecer nada a priori, mas apenas elaborar uma teoria da emergência desses sentidos e sociabilidades. Em último lugar, vale confrontar Saussure com o universalismo de uma teoria como o distribucionalismo americano. Na teoria bloomfieldiana, passa por empiria a manipulação das formas e a verificação de suas posições na frase, tirando do escopo teórico o sentido. Dessa maneira, o distribucionalista tem certeza de trabalhar com material objetivo. É louvável o esforço epistemológico de elaborar instrumentos que possam abarcar línguas de matrizes totalmente novas (Bloomfield estava atento à possível imposição de categorias indoeuropeias sobre outras famílias linguísticas, em especial sobre as línguas dos povos originários do território estadunidense). No entanto, de um ponto de vista saussuriano, tal abordagem 
seria radicalmente antiempírica, posto que ela ignora o que se postula como a realidade da língua: sua constituição psicológica no encontro entre som e sentido. Todas essas diferenças nos mostram que o saussurismo, na forma em que o apresento, se encontra deslocado entre as linhagens institucionalizadas dos estudos da linguagem. Não há categorias de língua préestabelecidas; com efeito, nem mesmo às línguas é garantida autonomia ontológica indiscutida, como vimos na discussão sobre a linguística geográfica.

O aparato teórico forjado a partir dessa leitura das ideias saussurianas parece nos habilitar para fazer com que línguas e culturas sejam mais do que ecos umas das outras, objetos portadores de categorias transcendentais recorrentes (substantivos, objetos indiretos, orações subordinadas adverbiais). O principal desafio de Saussure à gramática tradicional é lhe exigir que reapresente os fundamentos de seus conceitos a cada língua a ser estudada.

Há um desafio ainda maior que esse saussurismo parece nos colocar explicitamente, em essência tão científico quanto político. Por mais que se tente, os conceitos saussurianos sempre parecem se colocar em um impasse frente à dimensão desejada pelo Estado, isto é, quando se tenta fazer linguística de uma língua nacional que busca estabilidade, homogeneidade e dominância. Vale relembrar que nos exemplos de Saussure citados anteriormente, a língua já não é mais propriamente a mesma de um vilarejo até o próximo, que dirá em um território nacional inteiro. Mesmo levando em conta a heterogeneidade constitutiva da língua, chega um momento, como diz Saussure, em nossa jornada de vilarejo em vilarejo que já não mais compreendemos bem o que está sendo falado. Em suma, me parece que o instrumental teórico do saussurismo, ao menos na forma que me interessou neste trabalho, é mais apto para lidar com um recorte espaço-temporal que delimite comunidades de línguas, vocabulários, instituições. Uma passagem de Mil platôs parece afirmar categoricamente a base filosófica dessa possível ciência da linguagem:

Não há língua em si, nem universalidade da linguagem, mas um concurso de dialetos, línguas locais, gírias, línguas especiais. Não há falante-ouvinte ideal, bem como comunidade linguística homogênea. [...] Não há língua-mãe, mas tomada de poder de uma língua dominante em uma multiplicidade política (DELEUZE; GUAT'TARI, 1980, p. 14).

Me parece possível pensar o saussurismo como a ciência desses remendos de dialetos e jargões que não cessam de se diferenciar e multiplicar. Uma linguística que se pergunta que 
mundo cada comunidade falante habita. Uma ciência que problematize o lugar da língua de dominação e suas estratégias para manter o seu lugar e que observe as línguas minoritárias em suas múltiplas estratégias de resistência, de fuga. Em suma, uma linguística das singularidades e multiplicidades em variação constante.

\section{Considerações finais}

O saussurismo proposto neste artigo não é o fim de uma teorização, mas o início. Nas palavras de Henri Meschonnic, "Saussure é e permanece o ponto de partida de uma historicização radical da linguagem, das línguas, dos discursos, que resta por fazer” (2005, p. 10, tradução minha). Perseguir o caminho indicado por esse ponto de partida não é uma tarefa evidente.

Mostrei ao longo deste trabalho como Ferdinand de Saussure nos convida a superar as formas tradicionais de encarar as línguas e também com que instrumentos ele pode nos equipar para realizar essa tarefa. Coloquei especial ênfase na concepção da temporalidade em sua teoria, por acreditar que aí está o ponto em que não só ele se diferencia de outros linguistas, mas cria um regime de cientificidade único para a linguística por inteiro, assim como para as ciências do homem. Me foquei também no conceito de analogia e no de virtualidade, pois penso que nesses está concentrado o esforço de Saussure de explicitar o que é único na atividade linguageira. O mapa que desenhei para vagar dentro do saussurismo, ainda incompleto por não tratar em detalhes do resto da obra do genebrino, cria caminhos também para além dele, na forma de uma metafísica da linguagem única.

Entre as limitações da interpretação estruturalista e a rejeição de Saussure junto aos "pós-estruturalistas" (em sentido cronológico), a teoria do discurso, do falante, do sistema linguístico em movimento, latente na obra saussuriana nunca se realizou. Se o século XX foi o século de Saussure, na forma da metafísica do signo do estruturalismo, o século XXI tem o potencial de ser um novo século saussuriano, mas agora baseado sobre um pensamento em torno do sistema, da analogia, da virtualidade, do valor, do associativo, enfim, da multiplicidade. 


\section{Referências}

CHISS, J.-L. Synchronie/Diachronie: méthodologie et théorie en linguistique. Langages, v. 12, no 49, p. 91-111, 1978.

CHOI, Yong-Ho. La valeur en discours chez Saussure. L'information grammaticale, $\mathrm{n}^{\circ}$ 95, p. 50-53, 2000.

DELEUZE, G.; GUATTARI, F. Mille plateaux. Paris: Éditions de minuit, 1980.

MESCHONNIC, H. Critique du rythme: anthropologie historique du langage. Lagrasse:

Verdier, 1982.

Saussure ou la poétique interrompu. Langages, v. 39, no 159, p. 10-18, 2005.

NORMAND, C. L'arbitraire du signe comme phénomène de déplacement. Dialectiques, $\mathrm{n}^{\circ}$ 1-2, p. 109-126, 1973.

LATOUR, B. Jamais fomos modernos. São Paulo: Editora 34, 2011.

PUECH, C. L'émergence de la notion de "discours" en France et les destins du saussurisme. Langages, v. 39, n 159, p. 93-110, 2005.

SAUSSURE, F. Escritos de Linguística Geral. São Paulo: Cultrix, 2004.

. Curso de Linguística Geral. São Paulo: Cultrix, 2006. 


\begin{abstract}
This work approaches saussurean science in both a bistorical and philosophical way so as to offer a reading of Ferdinand de Saussure's oeure which highlights the conceptions of langue and language beld by the author, which are informed by concepts not so often emphasized in Saussurean studies, analogy and virtual specially. Through these concepts the linguistic phenomenon presents itself in a very unique form in Saussure's work, because it is an extremely fluid phenomenon that changes in space, in time and in the speech communities. Finally, I show how a considerable part of Saussure's interest, and for him the challenge in the linguist's work, lies in developing the conceptual instruments - and the philosophical understanding - which renders them capable of momentarily capturing the flowing of the fleeting and multiple langue in order to describe it from its immanent characteristics.
\end{abstract}

Keywords: Ferdinand de Saussure. Linguistic theory. Analogy. Virtual. Multiplicity

Recebido em: 30/04/2018.

Aceito em: 14/06/2018. 